\title{
Carbon Nanotubes: Smart Drug/Gene Delivery Carriers [Corrigendum]
}

Zare H, Ahmadi S, Ghasemi A, et al. Int J Nanomedicine. 2021;16:1681-1706.

The authors have advised the affiliation list on page 1681 is incorrect. The correct author list and affiliation is as follows.

\section{Hossein Zare ${ }^{1,2}$ \\ Sepideh Ahmadi ${ }^{3,4}$ \\ Amir Ghasemi ${ }^{5}$ \\ Mohammad Ghanbari ${ }^{6}$ \\ Navid Rabiee ${ }^{7}$ \\ Mojtaba Bagherzadeh ${ }^{7}$ \\ Mahdi Karimi ${ }^{8-12}$ \\ Thomas J Webster ${ }^{13}$ \\ Michael R Hamblin ${ }^{14}$ \\ Ebrahim Mostafavi ${ }^{13,15,16}$}

${ }^{1}$ Advances Nanobiotechnology and Nanomedicine Research Group (ANNRG), Iran University of Medical Sciences, Tehran, Iran; ${ }^{2}$ Biomaterials Group, Materials Science and Engineering Department, Iran University of Science and Technology, Tehran, Iran; ${ }^{3}$ Student Research Committee, Department of Medical Biotechnology, School of Advanced Technologies in Medicine, Shahid Beheshti University of
Medical Sciences, Tehran, Iran; ${ }^{4}$ Cellular and Molecular Biology Research Center, Shahid Beheshti University of Medical Sciences, Tehran, Iran; ${ }^{5}$ Department of Engineering, Durham University, Durham, DH1 3LE, United Kingdom; ${ }^{6}$ School of Metallurgy and Materials Engineering, University of Tehran, Tehran, Iran; ${ }^{7}$ Department of Chemistry, Sharif University of Technology, Tehran, Iran; ${ }^{8}$ Cellular and Molecular Research Center, Iran University of Medical Sciences, Tehran, Iran; ${ }^{9}$ Department of Medical Nanotechnology, Faculty of Advanced Technologies in Medicine, Iran University of Medical Sciences, Tehran, Iran; ${ }^{10}$ Oncopathology Research Center, Iran University of Medical Sciences, Tehran, Iran; ${ }^{11}$ Research Center for Science and Technology in Medicine, Tehran University of Medical Sciences, Tehran, MA, Iran; ${ }^{12}$ Applied Biotechnology Research Centre, Tehran Medical Science, Islamic Azad University, Tehran, MA, Iran; ${ }^{13}$ Department of Chemical Engineering, Northeastern University, Boston, MA 02115, USA; ${ }^{14}$ Laser Research Centre, Faculty of Health Science, University of Johannesburg, Doornfontein, 2028, South Africa; ${ }^{15}$ Stanford Cardiovascular Institute, Stanford University School of Medicine, Stanford, CA, USA; ${ }^{16}$ Department of Medicine, Stanford University School of Medicine, Stanford, CA, USA
International Journal of Nanomedicine

\section{Publish your work in this journal}

The International Journal of Nanomedicine is an international, peerreviewed journal focusing on the application of nanotechnology in diagnostics, therapeutics, and drug delivery systems throughout the biomedical field. This journal is indexed on PubMed Central, MedLine, CAS, SciSearch ${ }^{\circledR}$, Current Contents ${ }^{\mathbb{B}} /$ Clinical Medicine,
Journal Citation Reports/Science Edition, EMBase, Scopus and the Elsevier Bibliographic databases. The manuscript management system is completely online and includes a very quick and fair peer-review system, which is all easy to use. Visit http://www.dovepress.com/ testimonials.php to read real quotes from published authors. 